Supporting Information

for

\title{
Sensitive Glycoprotein Sandwich Assays by the Synergistic Effect of In Situ Generation of Raman Probes and Plasmonic Coupling of Ag Core-Au Satellite Nanostructures
}

Xiaoshuang Bi, Xueyuan Li, Dong Chen, and Xuezhong Du*

Key Laboratory of Mesoscopic Chemistry (Ministry of Education), State Key Laboratory of Coordination Chemistry, Collaborative Innovation Center of Chemistry for Life Sciences, and School of Chemistry and Chemical Engineering, Nanjing University 210023, People's Republic of China

* Corresponding Author

E-mail:xzdu@nju.edu.cn 


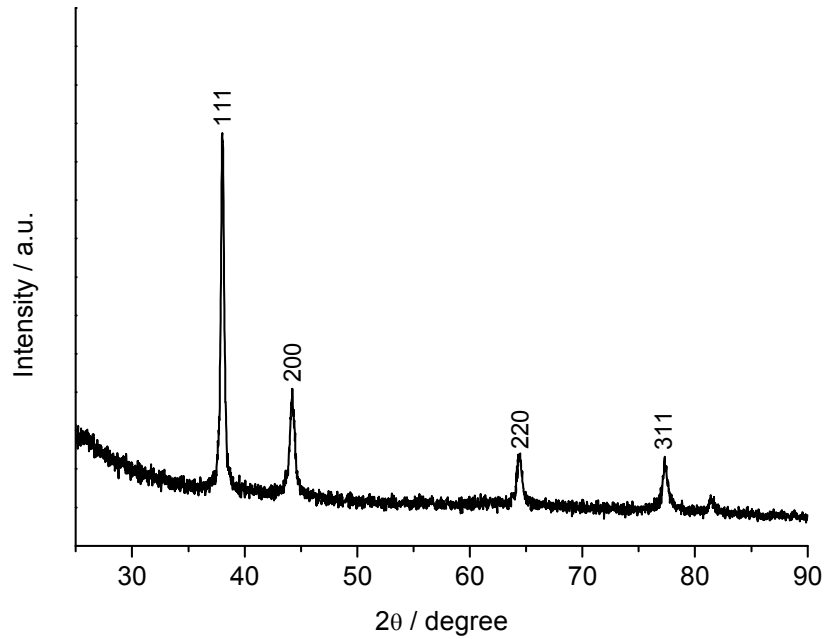

Figure S1. XRD patterns of Ag core-Au satellite/shell nanostructures. 


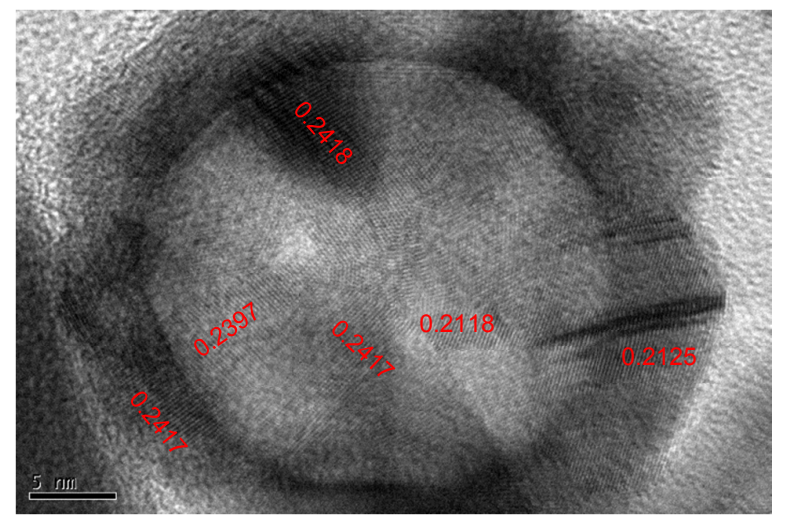

Figure S2. HRTEM image of Ag core-Au satellite/shell nanostructures. The red digits show lattice fringe spacings (in $\mathrm{nm}$ ) in the corresponding regions. 


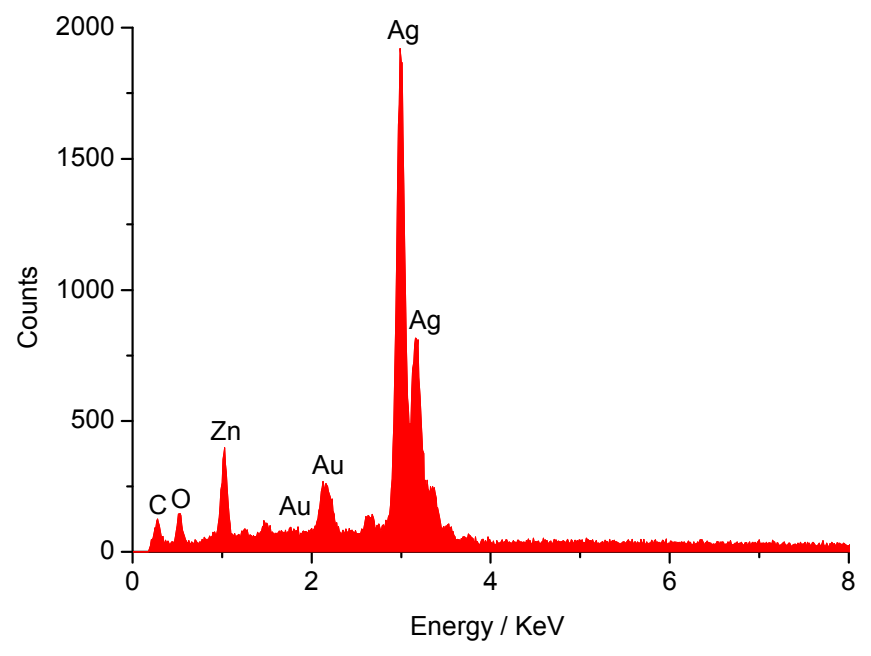

Figure S3. EDX spectrum of Ag core-Au satellite/shell nanostructures (Zn peak originated from the zinc slide). 


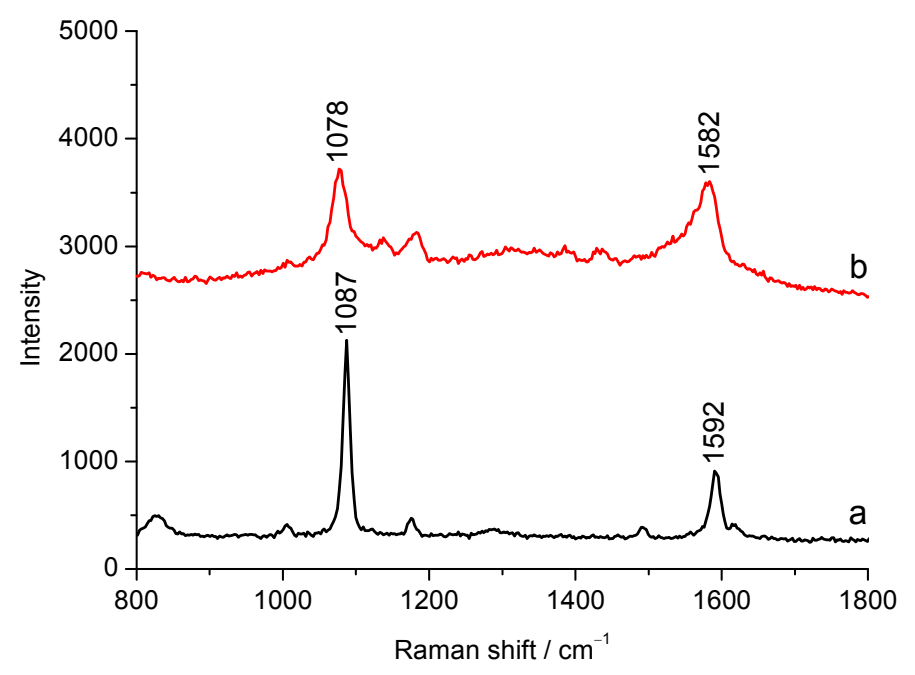

Figure S4. Normal Raman spectrum of PATP powder (a) and SERS spectrum of Langmuir-Blodgett (LB) monolayer of stearic acid transferred from aqueous PATP subphase $(0.5 \mathrm{mmol} / \mathrm{L})$ onto a smooth glass slide followed by AgNP staining (b) from reference $\mathrm{S} 1$ (Chem. Commun. 2013, 49, 8680-8682).

The ALINERS approach developed by our group ${ }^{\mathrm{S} 1}$ was used to obtain true SERS spectrum of PATP. The stearic acid (octadecanoic acid) LB monolayer was transferred from aqueous PATP subphase onto a smooth glass slide followed by AgNP staining. The molecular recognition between the stearic acid monolayer and PATP occurred owing to the electrostatic interaction and hydrogen bonding, thus PATP was transferred onto the glass slide. The stearic acid monolayer acted as a spacer layer (ca. $2 \mathrm{~nm}$ ) to separate PATP from direct contact with AgNPs, thus the true SERS spectrum of PATP was available. 


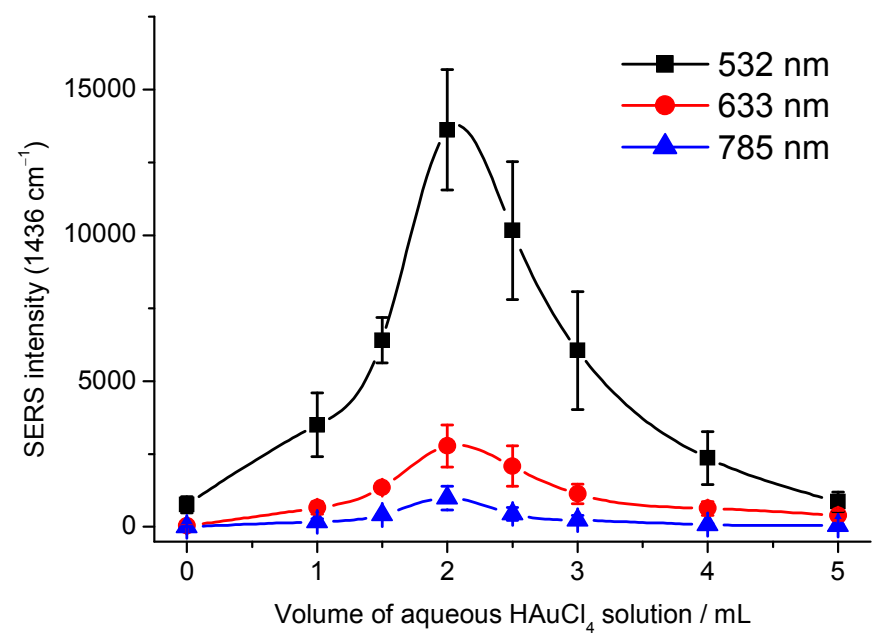

Figure S5. Intensity of the SERS peak at $1436 \mathrm{~cm}^{-1}$ the PATP-embedded Ag core-Au satellite SERS nanostructures under the excitation of different excitation wavelengths (532, 633 , and $785 \mathrm{~nm})$ as a function of volume of aqueous $\mathrm{HAuCl}_{4}$ solution $(0.465 \mathrm{mmol} / \mathrm{L})$ added. 

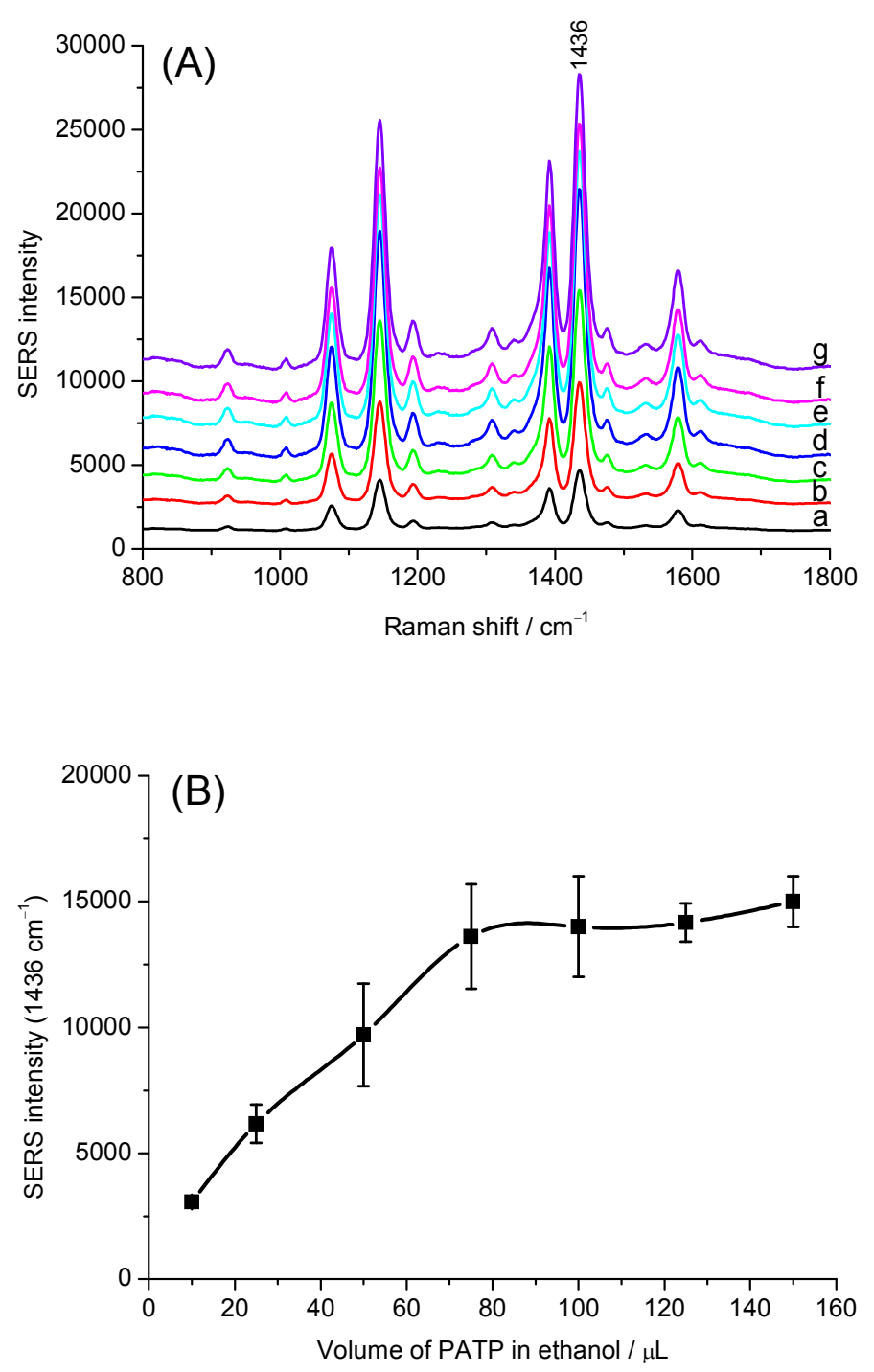

Figure S6. (A) SERS spectra of the PATP-embedded Ag core-Au satellite SERS nanostructures with addition of different volumes $(\mu \mathrm{L})$ of PATP in ethanol $(0.1 \mathrm{mmol} / \mathrm{L})$ : (a) 10; (b) 25; (c) 50; (d) 75; (e) 100; (f) 125; (g) 150. (B) Intensity of the SERS peak at 1436 $\mathrm{cm}^{-1}$ as a function of volume of PATP in ethanol $(0.1 \mathrm{mmol} / \mathrm{L})$. 


\section{Surface Coverage of Modified PATP on AgNP Surfaces}

The concentration of AgNPs in the hydrosol could be estimated to be $1.7 \times 10^{-11} \mathrm{~mol} / \mathrm{L}$ using UV-vis spectroscopy with a molar extinction coefficient of $3 \times 10^{11} \mathrm{~L} \mathrm{~mol}^{-1} \mathrm{~cm}^{-1}$. S2 If the amount of PATP added was smaller than the required amount for a full monolayer of PATP (molecular cross sectional area of $0.25 \mathrm{~nm}^{2}$ ) on the AgNP surfaces, it could be conjectured that the amount of modified PATP on the AgNP surfaces was equal to the amount of PATP added. The SERS tags were prepared by modification of AgNPs with PATP followed by immobilization of AuNPs. A total of $75 \mu \mathrm{L}$ of PATP in ethanol $(0.1 \mathrm{mmol} / \mathrm{L})$ was added to $22.5 \mathrm{~mL}$ of the AgNP hydrosol diluted from $12.5 \mathrm{~mL}$ of the original AgNP hydrosol under vigorous stirring for $10 \mathrm{~min}$ and then allowed to age without strirring for $2 \mathrm{~h}$. After that, the PATP-modified AgNP hydrosol was centrifuged at $6500 \mathrm{rpm}$ for $10 \mathrm{~min}$ and washed with double-distilled water twice, followed by redispersing in $10 \mathrm{~mL}$ of double-distilled water. The surface coverage $(\theta)$ of PATP on the AgNP surfaces was calculated on the basis of the total surface area $(S)$ of AgNPs and the amount $(n)$ of PATP added,

$$
\theta=0.25 n N_{\mathrm{a}} / S=0.25 n /\left(C_{\mathrm{Ag}} V \pi d^{2}\right)
$$

where $N_{\mathrm{a}}$ is Avogadro constant, $C_{\mathrm{Ag}}$ the concentration of AgNPs, $V$ the volume of AgNP hydrosol, and $d$ the average diameter of AgNPs. The surface coverage of PATP on the AgNP surfaces was calculated to be $75 \%$. 


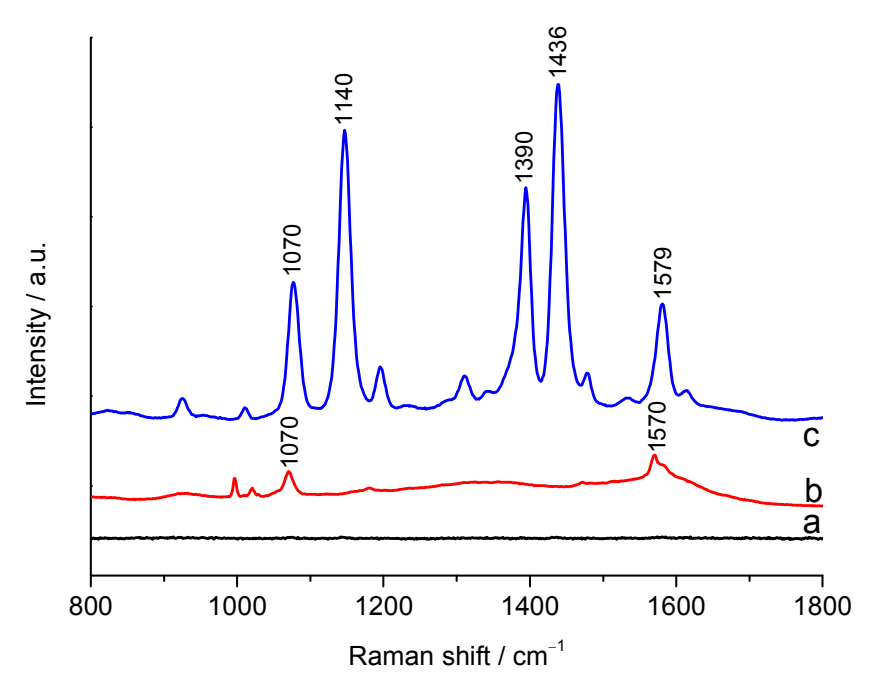

Figure S7. SERS spectra of (a) HRP-bound PMBA-modified smooth gold-coated silicon wafer, (b) HRP-bound PMBA-modified Ag core-Au satellite nanostructures, and (c) HRP-bound PMBA-modified SERS tags (PATP-embedded Ag core-Au satellite nanostructures).

No Raman signal could be detectable for the HRP-bound PMBA-modified smooth gold-coated silicon wafer, because the smooth gold-coated silicon wafer was SERS inactive. The SERS peaks of the HRP-bound PMBA-modified Ag core-Au satellite nanostructures resulted from PMBA. The SERS peaks of the HRP-bound PMBA-modified SERS tags (PATP-embedded Ag core-Au satellite nanostructures) resulted from PMBA and DMAB generated in situ from the photodimerization of PATP. It is noted that the intensities of the SERS peaks of DMAB were much stronger than those of PMBA. However, the SERS signals of glycoprotein assays could be available only when the glycoproteins were sandwiched between the PMBA-modified gold-coated silicon wafer and the PMBA-modified SERS tags (PATP-embedded Ag core-Au satellite nanostructures) through boronate linkages, otherwise the SERS tags could not be captured by the PMBA-modified gold-coated silicon wafer and no Raman signal could be detected. 
Table S1. Comparisons of the detection of a few types of glycoproteins.

\begin{tabular}{|c|c|c|c|c|c|c|}
\hline glycoprotein & ligand/substrate & $\mathrm{pH}$ & method & $\begin{array}{l}\text { concentration } \\
\text { range }\end{array}$ & $\begin{array}{l}\text { detection } \\
\text { limit }\end{array}$ & reference \\
\hline HRP & $\mathrm{PMBA} / \mathrm{Au}(\mathrm{SAM})$ & 7.4 & $\begin{array}{l}\text { sandwich-type } \\
\text { SERS assay }\end{array}$ & $\begin{array}{l}10 \mathrm{ng} / \mathrm{mL}-1 \mathrm{mg} / \mathrm{mL} \\
\left(0.23-2.3 \times 10^{7} \mathrm{nM}\right)\end{array}$ & $\begin{array}{l}10 \mathrm{ng} / \mathrm{mL} \\
(0.23 \mathrm{nM})^{a}\end{array}$ & this work \\
\hline HRP & $\begin{array}{l}\text { 3-aminophenylboronic } \\
\text { acid/Au (SAM) }\end{array}$ & 8.0 & electrochemistry & $\begin{array}{l}5 \mu \mathrm{g} / \mathrm{mL}-0.1 \\
\mathrm{mg} / \mathrm{mL}\end{array}$ & - & S3 \\
\hline HRP & $\begin{array}{l}\mathrm{PMBA} / \text { dendritic } \\
\mathrm{AuNPs} / \mathrm{Au}\end{array}$ & 8.5 & cyclic voltammetry & $2.5-2.5 \times 10^{4} \mathrm{nM}$ & $0.5 \mathrm{nM}^{b}$ & S4 \\
\hline$\alpha$-fetoprotein & $\begin{array}{l}\text { 3-aminophenylboronic } \\
\text { acid immunoaffinity }\end{array}$ & 8.5 & $\begin{array}{l}\text { flow injection } \\
\text { chemiluminescence }\end{array}$ & $10-100 \mathrm{ng} / \mathrm{mL}$ & $2.4 \mathrm{ng} / \mathrm{mL}^{b}$ & S5 \\
\hline $\begin{array}{l}\text { glucose } \\
\text { oxidase } \\
\text { transferrin }\end{array}$ & $\begin{array}{l}\mathrm{CuInS}_{2} \text { QDs- } \\
\text { rhodamine B }\end{array}$ & 8.5 & $\begin{array}{l}\text { fluorescence } \\
\text { resonance energy } \\
\text { transfer }\end{array}$ & $\begin{array}{l}0.335-67 \mathrm{nM} \\
0.69-34.5 \mathrm{nM}\end{array}$ & $\begin{array}{l}0.15 \mathrm{nM}^{b} \\
0.25 \mathrm{nM}^{b}\end{array}$ & S6 \\
\hline $\begin{array}{l}\text { HCMV } \\
\text { glycoprotein B }\end{array}$ & anti-HCMV antibody & 7.2 & $\begin{array}{l}\text { sandwich-type } \\
\text { immunoassay }\end{array}$ & $5-15 \mathrm{ng} / \mathrm{mL}$ & $3.3 \mathrm{ng} / \mathrm{mL}^{b}$ & S7 \\
\hline mucin 1 & $\begin{array}{l}\text { hairpin } \\
\text { oligonucleotide } \\
\text { switch-HRP/AuNPs }\end{array}$ & 7.4 & $\begin{array}{l}\text { differential pulse } \\
\text { voltammetry }\end{array}$ & $8.8-353.3 \mathrm{nM}$ & $2.2 \mathrm{nM}^{b}$ & S8 \\
\hline
\end{tabular}

${ }^{a}$ measured; ${ }^{b}$ calculated (at a signal-to-noise ratio of 3 )

HRP, horseradish peroxidase

MPBA, $p$-mercaptophenylboronic acid

SAM, self-assembled monolayer

AuNPs, Au nanoparticles

QDs, quantum dots

HCMV, human cytomegalovirus 


\section{References}

(S1)Kong, X.; Yu, Q.; Lv, Z.; Du, X.; Vuorinen, T. Identification of Molecular Recognition of Langmuir-Blodgett Monolayers using Surface-Enhanced Raman Scattering Spectroscopy. Chem. Commun. 2013, 49, 8680-8682.

(S2)McFarland, A. D.; Van Duyne, R. P. Single Silver Nanoparticles as Real-Time Optical Sensors with Zeptomole Sensitivity. Nano Lett. 2003, 3, 1057-1062.

(S3)Liu, S.; Wollenberger, U.; Halámek, J.; Leupold, E.; Stöcklein, W.; Warsinke, A.; Scheller, F. W. Affinity Interactions between Phenylboronic Acid-Carrying Self-Assembled Monolayers and Flavin Adenine Dinucleotide or Horseradish Peroxidase. Chem.-Eur. J. 2005, 11, 4239-4246.

(S4)Shen, D.; Liu, Y.; Fang, Y.; Li, P.; Yang, Z. A Sensor for Glycoproteins Based on Dendritic Gold Nanoparticles Electrodeposited on a Gold Electrode and Modified with a Phenylboronic Acid. J. Solid State Electrochem. 2015, 19, 563-568.

(S5)Wu, Y.; Zhuang, Y.; Liu, S.; He, L. Phenylboronic Acid Immunoaffinity Reactor Coupled with Flow Injection Chemiluminescence for Determination of $\alpha$-Fetoprotein. Anal. Chim. Acta 2008, 530, 186-193.

(S6)Gao, X.; Li, D.; Tong, Y.; Ge, D.; Tang, Y.; Zhang D.; Li, J. Highly Sensitive Fluorescence Detection of Glycoprotein Based on Energy Transfer between $\mathrm{CuInS}_{2}$ QDs and Rhodamine B. Luminescence 2015, 30, 1389-1394.

(S7)Pires, F.; Silva, H.; Domínguez-Renedo, O.; Alonso-Lomillo, M. A.; Arcos-Martínez, M. J.; Dias-Cabral, A. C. Disposable Immunosensor for Human Cytomegalovirus Glycoprotein B Detection. Talanta 2015, 136, 42-46.

(S8)Hu, R.; Wen, W.; Wang, Q.; Xiong, H.; Zhang, X.; Gu, H.; S.; Wang, Novel Electrochemical Aptamer Biosensor Based on an Enzyme-Gold Nanoparticle Dual Label for the Ultrasensitive Detection of Epithelial Tumour Marker MUC1. Biosens. Bioelectron. 2014, 53, 384-389. 